\title{
DO POEMA DRAMÁTICO SIMBOLISTA AO TEATRO DO ABSURDO: O NAVEGAR IMPRECISO DE FERNANDO PESSOA EM O MARINHEIRO
}

Glauco Cunha Cazé ${ }^{1}$

RESUMO: Este artigo tem por objetivo a análise do texto teatral "O Marinheiro" (1913), de Fernando Pessoa (1888-1935), defendendo a hipótese de que o dramaturgo português, influenciado que foi pelo teatro simbolista do belga Maurice Maeterlinck (1862-1949), antecipa em quase cinquenta anos características do Teatro do Absurdo, que tem início, de modo mais oficial, com os estudos do austríaco Martin Esslin (1918-2002) quando da publicação de seu livro homônimo em 1961.

PALAVRA-CHAVE: Pessoa, Teatro, Simbolismo, Absurdo.

ABSTRACT: This article takes as an objective the analysis of the theatrical text ' The Sailor ' (1913), of Fernando Pessoa (1888-1935), defending the hypothesis of which the Portuguese, influenced playwright who was for the symbolist theater of the Belgian Maurice Maeterlinck (1862-1949), anticipates in almost fifty years characteristics of the Theater of the Absurdity that has beginning, of more official way, with the studies of the Austrian Martin Esslin (1918-2002) when of the publication of his homonymic book in 1961 .

KEYWORDS: Pessoa, Theater, Symbolism, Absurdity.

\section{I}

Convencionou-se, de há muito, que a produção poética de Fernando Pessoa é o suporte privilegiado de sua verve genial e de sua excelência literária. Não obstante o lirismo precioso do eu mesmo, as contribuições poéticas - não menos preciosas - de suas muitas outras personas são vistas e revistas a cada nova edição proposta e propensa ao sucesso editorial.

Pensador inquieto, multifacetado e enigmático, produziu poesia labiríntica, mudando sempre a pergunta ao se avizinhar da resposta. Propondo reflexões que iam muito além de seu tempo, de seu espaço e de sua existência multissecular.

O exercício do diálogo em Pessoa se faz, entre outras experiências em prosa ficcional, no texto teatral "O Marinheiro", escrito entre os dias 11 e 12 de outubro de 1913 e publicado na edição número 01 da Revista Orpheu, em 1915; o qual, pela escassez de estudos, assume a função de corpus deste artigo acadêmico.

"O Marinheiro" apresenta-se como o navegar impreciso de Fernando Pessoa nas águas brumas da dramaturgia portuguesa do início do século XX. E por impreciso, leia-

\footnotetext{
${ }^{1}$ Mestrando em Teoria da Literatura pela Universidade Federal de Pernambuco - UFPE. Desenvolve pesquisas na área de Teatro e Mito.
} 
se: inconstante, volúvel, mutável; em oposição a inube, claro, sereno; não sendo aqui, em absoluto, sinônimo de má qualidade literária. Trata-se de texto teatral que, em princípio e de maneira abreviada, é visto como um exercício simbolista em prosa poética pouco ou quase nada apropriado à encenação teatral mais convencional. Repitase: de maneira abreviada, uma vez que os aparentes aspectos simbolistas impregnados no texto colaboraram para a antecipação e consolidação de elementos inovadores ao teatro moderno do século XX.

O teatro produzido na Europa de fins do século XIX é um teatro explicitamente simbolista, decadentista, regido pelo poeta, dramaturgo e ensaísta belga de língua francesa Maurice Maeterlinck (1862-1949), lido pelo escritor português, conforme registro da biblioteca virtual da casa de Fernando Pessoa. ${ }^{2}$ Leitura que, sem dúvida, influenciaria o fazer teatral de "O Marinheiro".

No texto de Pessoa, três mulheres confabulam sobre suas existências mergulhadas em intermináveis reminiscências. $\mathrm{O}$ corpo jacente de uma donzela vestida de branco é visto morto e depositado em um caixão que ocupa o centro do quarto que serve de cenário, único e suficiente.

O passado é convocado - não sem resistência - a conduzir e estimular as reflexões das três mulheres, supostamente irmãs, enquanto "não raia sanguínea e fresca a madrugada." 3

São reflexões sobre a infância, sobre sonhos, sobre angústias e esperanças, sobre vida e morte. Temas que fortalecem, sem dúvida, o caráter estático do texto teatral de Pessoa e revelam uma atmosfera onírica e filosófica, concedendo ao texto um caráter específico de leitura dramática em oposição ao de encenação mais dinâmica. Nada de novo até então, uma vez que a proposta do descompasso cênico é defendida pelo próprio Fernando Pessoa quando denomina seu texto teatral como um "Drama estático em um quadro" ". Mesmo quando a força dramática parece solicitar uma agitação mais corporal, o dramaturgo intercede em favor do sonho, da contemplação mais densa das palavras, do inerte e, por conseguinte, da absorta posição cênica.

\footnotetext{
${ }^{2}$ http://casafernandopessoa.cm-lisboa.pt/bdigital/index/aut/M/maeterlinckmaurice.htm Acessado em 03 de junho de 2011.

${ }^{3}$ Referência ao poema "As pombas", do poeta parnasiano brasileiro Raimundo Correia.

${ }^{4}$ Afirmação apresentada por Massaud Moisés no livro O Banqueiro Anarquista e outras prosas, p. 17.
} 
PRIMEIRA VELADORA - Não dizeis senão palavras. É tão triste falar! É um modo tão falso de nos esquecermos! ... Se passeássemos?...

TERCEIRA - Onde?

PRIMEIRA - Aqui, de um lado para o outro. Às vezes isso vai buscar sonhos.

TERCEIRA — De quê?

PRIMEIRA — Não sei. Porque o havia eu de saber?

(uma pausa)

$[\ldots]$

SEGUNDA - Contemos contos umas às outras... Eu não sei contos nenhuns, mas isso não faz mal... Só viver é que faz mal... Não rocemos pela vida nem a orla das nossas vestes... Não, não vos levanteis. Isso seria um gesto, e cada gesto interrompe um sonho... Neste momento eu não tinha sonho nenhum, mas é-me suave pensar que o podia estar tendo... Mas o passado - por que não falamos nós dele?

PRIMEIRA - Decidimos não o fazer... Breve raiará o dia e arrepender-nos-emos... Com a luz os sonhos adormecem... O passado não é senão um sonho... De resto, nem sei o que não é sonho. Se olho para o presente com muita atenção, parece-me que ele já passou... O que é qualquer cousa? Como é que ela passa? Como é por dentro o modo como ela passa?... Ah, falemos, minhas irmãs falemos alto, falemos todas juntas... O silêncio começa a tomar corpo, começa a ser cousa... Sinto-o envolver-me como uma névoa... Ah, falai, falai!...

SEGUNDA - Para quê?... Fito-vos a ambas e não vos vejo logo... Parece-me que entre nós se aumentaram abismos... Tenho que cansar a ideia de que vos posso ver para poder chegar a ver-vos... Este ar quente é frio por dentro, naquela parte que toca na alma... [...] Ainda há pouco, quando eu não pensava em nada, estava pensando no meu passado. (PESSOA apud MOISÉS, 1998, p. 67, 68 e 69)

Toda essa construção mais devotada aos princípios simbolistas no texto - que conduz o navegar impreciso de "O Marinheiro" - pode ser conferida em significativas preocupações com a sonoridade das palavras, com a indefinição do tempo, com a opção pela não nominação das personagens, com a sugestão em vez da informação e na opção pelo mistério. Marcas do decadentismo europeu comum ao fim do século XIX, começo do século XX, que certamente influenciou a escrita do dramaturgo, não obstante sua inclinação natural para um surrealismo psíquico.

PRIMEIRA VELADORA - Ainda não deu hora nenhuma.

SEGUNDA - Não se pode ouvir. Não há relógio aqui perto.

Dentro em pouco deve ser dia.

TERCEIRA — Não: o horizonte é negro.

[...]

TERCEIRA — Por que não haverá relógio neste quarto? 
SEGUNDA - Não sei... Mas assim, sem o relógio, tudo é mais afastado e misterioso. A noite pertence mais a si própria... Quem sabe se nós poderíamos falar assim se soubéssemos a hora que é? (PESSOA apud MOISÉS, 1998, p.66 e 68.)

O que chama a atenção, no entanto, nessa menos investigada dramaturgia de Fernando Pessoa, além da utilização dos temas preferidos do ortônimo no discurso das personagens, é a antecipação expressiva, significativa de elementos particulares da estética teatral intitulada Teatro do Absurdo, que somente surgiria nos anos de 1950, trinta e cinco anos após a publicação do texto dramático do poeta maior do modernismo português.

\section{II}

O termo, expressão ou adjetivo absurdo parece não ser de todo desproporcional se tatuado ao espírito do múltiplo escritor Fernando Pessoa. Em seu estudo sobre o teatro do dramaturgo brasileiro da segunda metade do século XIX Qorpo-Santo, o ator, autor e professor da escola de arte dramática EAD/USP, Eudinyr Fraga (1988, p. 27), explica que absurdo, literalmente quer dizer fora de harmonia. De acordo com uma das versões do dicionário eletrônico Aurélio, absurdo significa desarmonia em contexto musical, em relação a uma razão ou a uma propriedade; irracional, ilógico, quimera, utopia. $^{5}$ Do latim, absurdu, ou seja, contrário à razão, contraditório, disparatado. Definições que não atingiriam de maneira ofensiva o caráter desassossegado do escritor português.

A expressão Teatro do Absurdo tem início com os estudos de Martin Esslin (1918-2002), austríaco de nascimento, radicado na Inglaterra, por ocasião da publicação de seu livro homônimo, em 1961. E a hipótese de antecipação à estética teatral apresentada por Esslin, na obra "O Marinheiro", de Fernando Pessoa, fundamenta-se nos conceitos do próprio formulador da estética, quando em seu mais importante livro, no capítulo intitulado "O Significado do Absurdo", defende que,

como o teatro do absurdo não tem por objetivo transmitir informações ou apresentar problemas ou destinos de personagens que existam fora

\footnotetext{
5 Novo Dicionário Eletrônico Aurélio versão 5.0 - corresponde à $3^{\mathrm{a}}$. ed., $1^{\mathrm{a}}$. impressão da Editora Positivo, revista e atualizada do Aurélio Século XXI, O Dicionário da Língua Portuguesa, contendo 435 mil verbetes, locuções e definições. (C2004 by Regis Ltda.
} 
do mundo interior do autor, como ele não propõe teses e nem debate de proposições ideológicas, ele não se preocupa com a representação de acontecimentos, nem com a narração do destino ou das aventuras das personagens, mas apenas com a apresentação da situação básica de um indivíduo. É um teatro de situação, em oposição a um teatro de acontecimentos em sequência, e por isso mesmo usa uma linguagem baseada na conformação de imagens concretas mais do que em argumentos ou falas discursivas. E já que está tentando apresentar uma sensação de existência, não pode investigar e muito menos resolver problemas de conduta ou de moral. (ESSLIN, 1966, pág.349)

O que se percebe na leitura dessa introdutória definição ao Teatro do Absurdo é que o dramaturgo Fernando Pessoa, na escrita de seu "O Marinheiro", lança mão desses princípios ilógicos e sensoriais característicos dos textos ditos absurdos sem que, em momento algum, se aperceba - ao menos de maneira explícita - que estaria corroborando uma nova possibilidade ao fazer teatral, a princípio, díspar do que até então era realizado na Europa finissecular.

Portugal e alguns países europeus produziam, em escala maior, o chamado teatro realista/naturalista/simbolista; enquanto que, de maneira inicial, em Paris já efervescia o teatro de Vanguarda Poética, que em alguns aspectos se assemelha a proposta vindoura do Absurdo quando propõe um universo ilógico e onírico no desenvolvimento do texto com interferências decadentistas, embora com um alto grau de ironia e um humor bem distinto. Destacavam-se nesse teatro de Vanguarda Poética os dramaturgos Michael de Ghelderode, Jacques Audiberti, Georges Neveux, entre outros. Enquanto que a representação mais legítima do Teatro do Absurdo é encontrada no irlandês Samuel Beckett (Esperando Godot), no romeno Eugène Ionesco (A Cantora Careca), no russo Arthur Adamov (Todos contra todos) e o francês Jean Genet (O Balcão).

Porém, se são estéticas teatrais próximas em características, como não supor, então, que o teatro de Fernando Pessoa antecipa a Vanguarda Poética e não o Absurdo, uma vez que a poesia lhe é infinitamente mais peculiar? A resposta não está nas similitudes, mas nas diferenças. A Vanguarda Poética vai se dedicar, essencialmente, a um lirismo protestante que garganteia a falta de lógica de um mundo que prenuncia uma guerra estúpida e os deslocamentos do sujeito moderno, lançando mão da ironia, de um humor sarcástico, filiando-se, assim, ao dadaísmo, ao surrealismo e a outros ismos de um agitado início de século XX. Já o Absurdo, herdeiro desse non sense vanguardista, vai se focar, em prioridade, nas angústias existenciais mais profundas do $e u$; e de 
maneira verborrágica, vai jorrar os problemas mentais do sujeito, quer pelo sonho, quer pela realidade, quer pelo passado incerto. São inquietações que brotam do mental. E tudo em Fernando Pessoa é mental. É o que defende Leyla Perrone-Moisés em seu estudo sobre o Livro do Desassossego quando afirma que

As grandes aventuras, como sempre, em Pessoa são mentais. Mas o que é também característico de Pessoa, essas aventuras mentais não são meras compensações imaginárias de um real insatisfatório; são o mergulho nauseado da consciência em sua própria insatisfação, para dissecar cada sensação e esmiuçar cada ideia até a beira da destruição, da autodestruição. (MOISÉS, 1986, p. 16)

Em “O Marinheiro", Fernando Pessoa surge no entrecortar dessas estéticas, apresentando um teatro ainda simbólico negritado por aventuras mentais e por confabulações introspectivas, inclusive, se antecipando em explicações defensivas, por ser, seu texto, desprovido de elementos cênicos que garantam sua ampla funcionalidade técnica, sua teatralidade absoluta; deixando escapar assim, a antecipação de certo absurdo dramático estético; certa impressão no navegar de seu Marinheiro. O que, para o Professor Eudinyr Fraga, no capítulo “Absurdidade”, nada mais natural e próprio do Teatro do Absurdo.

Nesse novo teatro não se fala do absurdo, ele é mostrado ao espectador tão como é, ou seja, o próprio significante (a presença do ator, as palavras, os gestos, os silêncios, enfim todos os signos que surgem no palco) traz em si o significado que pretende mostrar. Não é um discurso sobre alguma coisa, é a própria coisa referendada. Assim sendo, o teatro do absurdo é um antiteatro, no sentido de que recusa, conscientemente, qualquer mecânica de uma peça tradicional: trama, caracterização psicológica das personagens, progressão da ação visando atingir um clímax, e onde os espectadores se identificam com o que se passa em cena. Não há conflito, se entendermos conflitos como o choque de vontades livres. É uma tentativa de teatro puro, onde o palco não se transforma em tribuna ou central de correios enviando mensagens. (FRAGA, 1988, p. 29-30)

O Teatro do Absurdo é uma forma dramática moderna que utiliza, para a criação do enredo, das personagens e do diálogo, elementos do ilógico com o objetivo de reproduzir diretamente o desatino e a falta de soluções em que estão imersos o homem e a sociedade. As personagens estão presas em situações sem solução, forçadas a executar ações repetitivas e sem sentido. O Teatro do Absurdo foca principalmente o 
comportamento humano, deflagrando a relação das pessoas e seus atos non sense. É exatamente com essas características que se apresenta o texto "O Marinheiro", de Fernando Pessoa, quase cinquenta anos antes da essência maior dessa estética moderna da dramaturgia ocidental vir à cena.

\section{III}

Seria o próprio Fernando Pessoa o marinheiro de seu texto teatral? Que sua dramaturgia é marcada por uma prosa essencialmente poética e estática já foi efetivamente comprovado e referendado, inclusive pelo próprio dramaturgo. Que as mais incoerentes discussões arraigadas pela mente, pelo passado e pelo sonho constituem a sustentação cênica de seu teatro é constatação vivenciada na leitura. Que as reflexões poéticas sugeridas no texto partam do espírito inquieto e da mente obtusa do Fernando Pessoa ortônimo é sugestão aceita por compatibilidade. Ainda assim, o que há em sua dramaturgia que mais se aproxime de suas verdades e aponte para sua genialidade plural que começa a se elevar? Que relações existem entre a figura do marinheiro e seu próprio criador? Fernando Pessoa finge as dores de amores de seu personagem; ou as sente verdadeiramente, transferindo à figura do marinheiro suas incompletudes, uma vez que grande parte da genialidade do escritor português se deve ao seu estado de inacabamento e sofrimento? Que relações há entre estas questões propostas e a imprecisão do texto teatral?

Há, supostamente, mais verdades que mentiras nessas aproximações entre Pessoa e seu personagem. A própria escolha em apresentar o marinheiro pelo viés da prosa confirma essa suposição. Em prosa, consoante Lourenço (2008, p. 116) "significa, segundo a indicação explícita do próprio Pessoa, em menos mentira, consubstancial a toda expressão poética."

O que se percebe quando da aparição do personagem marinheiro no sonho da segunda veladora são as marcas mais pontuais dos textos de Fernando Pessoa ortônimo. Estão presentes nos discursos os temas da loucura, do mar, da pátria, do fingimento e o da necessidade de ser muitos.

A segunda veladora apresenta, já no início do texto, reflexões sobre o tema da pátria, o qual será reforçado quando o marinheiro for devidamente convocado. 
janela. A janela dava para o mar e às vezes havia uma ilha ao longe... Muitas vezes eu não fiava; olhava para o mar e esquecia-me de viver. Não sei se era feliz. Já não tornarei a ser aquilo que talvez eu nunca fosse...

[...]

SEGUNDA - Só o mar das outras terras é que é belo. Aquele que nós vemos dá-nos sempre saudades daquele que não veremos nunca... (PESSOA apud MOISÉS, 1998, p. 67-68)

O marinheiro sofre a ausência de sua pátria perfeita e, como numa solução mágica, resolve construir - sonho - uma nova pátria na ilha deserta em que agora se encontra isolado. De maneira ordenada vai construindo a imagem de um possível "quinto império" que, sem dúvida, pavimentará os propósitos ainda embrionários do poeta português para sua grande obra Mensagem, escrita entre os anos vinte e trinta. $\mathrm{O}$ marinheiro surge do sonho incompleto da segunda veladora e é apresentado de maneira vaga; como vagos são os discursos.

SEGUNDA - Sonhava de um marinheiro que se houvesse perdido numa ilha longínqua. Nessa ilha havia palmeiras hirtas, poucas, e aves vagas passavam por elas... Não vi se alguma vez pousavam... Desde que, naufragado, se salvara, o marinheiro vivia ali... Como ele não tinha meio de voltar à pátria, e cada vez que se lembrava dela sofria, pôs-se a sonhar uma pátria que nunca tivesse tido: pôs-se a fazer ter sido sua uma outra pátria, uma outra espécie de país com outras espécies de paisagens, e outra gente, e outro feitio de passarem pelas ruas e de se debruçarem das janelas... Cada hora ele construía em sonho esta falsa pátria, e ele nunca deixava de sonhar, de dia à sombra curta das grandes palmeiras, que se recortava, orlada de bicos, no chão areento e quente; de noite, estendido na praia, de costas e não reparando nas estrelas.

[...]

SEGUNDA - Um dia, que chovera muito, e o horizonte estava mais incerto, o marinheiro cansou-se de sonhar... Quis então recordar a sua pátria verdadeira..., mas viu que não se lembrava de nada, que ela não existia para ele... Meninice de que se lembrasse, era a na sua pátria de sonho; adolescência que recordasse, era aquela que se criara... Toda a sua vida tinha sido a sua vida que sonhara... E ele viu que não podia ser que outra vida tivesse existido... Se ele nem de uma rua, nem de uma figura, nem de um gesto materno se lembrava... E da vida que lhe parecia ter sonhado, tudo era real e tinha sido... Nem sequer podia sonhar outro passado, conceber que tivesse tido outro, como todos, um momento, podem crer... Ó minhas irmãs, minhas irmãs... Há qualquer coisa, que não sei o que é, que vos não disse... Qualquer coisa que explicaria isto tudo... A minha alma esfria-me... Mal sei se tenho estado a falar... Falai-me, gritai-me, para que eu acorde, para que eu saiba que estou aqui! Ante vós e que há coisas que são apenas sonhos... (PESSOA apud MOISÉS, 1998, p.73, 75-76) 
Certo sebastianismo se apodera do texto, e os sentimentos patrióticos do dramaturgo são postos em cena na voz de personagens que sonham o sonho do marinheiro e do escritor. Entretanto, em outros diálogos não se pode afirmar se os sonhos são os mais legítimos sentimentos do dramaturgo ou se fingimento encenado por muitos de seus "eus", num aflorar do Drama em Gente que alimenta a heteronímia.

Passagens como "quando falo demais começo a separar-me de mim e a ouvirme falar'; 'que voz é essa com que falais?... É de outra... Vem de uma espécie de longe'; 'quando a onda se espalha e a espuma chia, parece que há mil vozes mínimas a falar'; 'quando eu sorria, os meus dentes eram misteriosos na água... Tinham um sorriso só deles, independente do meu'; 'quem é que eu estou sendo? Quem é que está falando com minha voz?" são, sem dúvida, manifestações aflitas de uma multiparidade muito pessoana.

A imprecisão se torna palavra de ordem no texto do escritor português. Não se pode precisar quem sofre, quem fala, quem ouve. Não se pode precisar quem é o marinheiro, quem são as donzelas. As imagens são criadas por sonhos. No Teatro do Absurdo, o espectador é confrontado com a loucura da condição humana. Mais uma ligação do teatro pessoano com o absurdo.

O Teatro do Absurdo apenas transmite a intenção mais íntima e pessoal de um poeta, sua sensação de existência particular, sua visão individual do mundo. Tal é a temática do Teatro do Absurdo, e ela determina sua forma, que deve, necessariamente, representar uma convenção de palco basicamente diversa do teatro realista de nosso tempo. (ESSLIN, 1966, p.349)

Toda esta imprecisão é conferida, por exemplo, numa das obras iniciais e de maior repercussão do Teatro do Absurdo no século XX, Esperando Godot, de Samuel Beckett (ganhador do prêmio Nobel de Literatura no ano de 1969). A expressão "Esperando Godot" era utilizada em tempos passados para indicar algo impossível, ou uma espera infrutífera. Representação do homem eternamente a espera. Samuel Beckett escreveu a peça em 1949 e só veio a publicá-la no ano de 1952, em francês. Em 1955, ele mesmo publicou a versão escrita em inglês. O enredo baseia-se na falta de comunicação entre os personagens e na pausa do silêncio da espera de algo que não se resolve. 
PRIMEIRO ATO

Caminha em um descampado, com árvore. Entardecer. ESTRAGON, sentado no chão, trata de descalçar-se com ambas as mãos. Detem-se e, esgotado; descansa, ofegando; volta a começar. Do mesmo modo. Entra VLADIMIR

ESTRAGON. (Renunciando novamente.) - Não há nada a fazer. VLADIMIR. (Aproximando-se de passos curtos e rígidos, separadas as pernas.) - Começo a acreditá-lo. (Fica imóvel) Durante muito tempo resisti a acreditá-lo, dizendo-me - "VLADIMIR, seja razoável; ainda não tentou tudo." $\mathrm{E}$ reemprendia a luta. (Reconcentrase, pensando na luta. Ao ESTRAGON) Assim que outra vez aí?

ESTRAGON. - Te pareces?

VLADIMIR. - Me alegra voltar a ver-te. Acreditava que te foras para sempre.

ESTRAGON. - E eu.

VLADIMIR. - Como celebraremos este encontro? (Reflete) Vens que te beijo. (Estende a mão ao ESTRAGON)

ESTRAGON. (Irritado) - Logo, logo.

(SILÊNCIO)

ESTRAGON. - Mas que sábado? É hoje sábado? Não seria melhor domingo? Ou segunda-feira? Ou sexta-feira?

VLADIMIR. (Olhando enlouquecido ao redor dele como se a data estivesse escrita na paisagem.) - Não é possível.

ESTRAGON. - Ou quinta-feira.

VLADIMIR. - O que fazemos?

ESTRAGON. - Se a noite se machucou num balde, já pode estar seguro de que hoje não vêm.

VLADIMIR. - Mas, dizes, que nós viemos ontem à noite.

ESTRAGON. - Posso me equivocar. (Pausa.) Queres que nos calemos um pouco?

VLADIMIR. - (Debilmente.) Bom. (ESTRAGON senta-se no chão. VLADIMIR percorre com passos longos a cena agitadamente. De quando em quando se detém para observar o horizonte. ESTRAGON dorme. VLADIMIR para diante de ESTRAGON.) Gogo... (Silêncio.) Gogo... (Silêncio.) Gogo! (ESTRAGON acorda sobressaltado.) ${ }^{6}$

O enredo é de difícil compreensão para o público da época: dois vagabundos esperam infinitamente, ao pé de uma árvore, por um indefinível Sr. Godot, que jamais comparecerá ao encontro marcado. Os dois dias em que a peça se passa são absolutamente idênticos: a situação permanece a mesma do começo ao fim; num vácuo dramático que revela uma originalidade teatral sem precedentes na história da dramaturgia universal.

\footnotetext{
${ }^{6}$ http://solivrosparadownload.blogspot.com/2007/05/samuel-beckett-esperando-godot.html
} 
São marcas textuais que se aproximam, por demais, do universo ilógico do sonho, da imprecisão e angústias existenciais proposto pelo dramaturgo português trinta e cinco anos antes da estética desenvolvida por Beckett.

Fernando Pessoa, desta feita, em sua dramaturgia onírica de 1913, apresenta um teatro de afinidades com a estética do Absurdo - dos nos de 1950 - e navega por mares sempre dantes navegados. Os mares do fingimento poético, dos sonhos incompletos, do passado revivido, da loucura assumida (como na pela do Dr. F. Antunes, ainda muito jovem), da multiplicidade de personas, do inquietismo intelectual, dos sons e dos silêncios. São mares que fazem de seu texto teatral um exemplo de antecipação ao moderno; com uma enorme capacidade de unir poesia e prosa num mesmo ambiente literário e de qualidade.

Se o espaçamento temporal entre o teatro simbolista produzido na Europa quando da escrita de "O Marinheiro" e a definição do absurdo catalogada por Esslin quase meio século adiante não configura num caráter inovador ao texto de Pessoa. Que pelo menos se registre a maneira vanguardista desse menos estudado dramaturgo e sua imensa contribuição ao teatro moderno do século XX.

\section{REFERÊNCIAS}

BECKETT, Samuel. Esperando Godot. Disponível em:

http://solivrosparadownload.blogspot.com/2007/05/samuel-beckett-esperandogodot.html> Acesso em 07 de junho de 2011.

CASA DE FERNANDO PESSOA. Disponível em:

<HTTP://www.casadefernandopessoa.com.br/index.asp> Acesso em 07 de junho de 2001.

ESSLIN, Martin. O Teatro do Absurdo. Trad. Bárbara Heliodora. 3. ed. Rio de Janeiro: Zahar Editores, 1966.

FRAGA, Eudinyr. Qorpo-Santo: surrealismo ou absurdo. São Paulo: Editora Perspectiva, 1988.

FURASTÉ, Pedro Augusto. Normas Técnicas para o Trabalho Científico: explicitação das normas da ABNT. 15. Ed. Porto Alegre: s.ed., 2011. 
LOURENÇO, Eduardo. Fernando, rei da nossa Baviera. Lisboa: Gradiva, 2008.

PERRONE-MOISÉS, Leyla. Introdução ao Desassossego. In: Livro do Desassossego por Bernardo Soares. São Paulo: Brasiliense, 1986.

PESSOA, Fernando. O Marinheiro. In: MOISÉS. Massaud, O Banqueiro Anarquista e outras Prosas, 1998.

ROUBINE, Jean-Jacques. Introdução às grandes teorias do teatro. Trad. André Telles. Rio de Janeiro: Jorge Zahar, 2003.

QUILICI, Cassiano Sydow. Antonin Artaud: Teatro e Ritual. São Paulo: Fapesp, 2004. 